\title{
Peningkatan Kompetensi Melalui Kolaborasi : Suatu Tinjauan Teoritis Terhadap Guru
}

\author{
Yuni Kasmawati \\ Manajemen, Fakultas Ekonomi dan Bisnis Universitas Budi Luhur \\ Email: yuni.kasmawati@budiluhur.ac.id
}

\begin{abstract}
Yuni Kasmawati, 2020. Teacher collaboration is a means for teachers to improve their competence in the form of knowledge, skills and experience. Competence is needed by teachers to support their performance. This study aims to examine the improvement of teacher competency through the teacher collaboration approach. The study was conducted using the literature review method by utilizing the publication of previous research results. The results of the study concluded that teacher collaboration has a positive impact not only on teachers, but also on students and schools. From the teacher's side, collaboration plays a role in increasing competencies in the form of teacher's knowledge, skills and experience. Furthermore, teacher competence will play a role in supporting teacher performance which will ultimately improve student achievement.
\end{abstract}

Keywords : Competence, Collaboration, Theoretical Review

\begin{abstract}
Abstrak. Yuni Kasmawati, 2020. Kolaborasi guru merupakan sarana bagi guru untuk meningkatkan kompetensinya baik berupa pengetahuan, ketrampilan maupun pengalaman. Kompetensi dibutuhkan guru untuk menunjang kinerjanya. Penelitian ini bertujuan untuk menelaah peningkatan kompetensi guru melalui pendekatan kolaborasi guru. Penelitian dilakukan dengan metode tinjauan literatur dengan memanfaatakan publikasi hasil penelitian sebelumnya. Hasil penelitian menyimpulkan bahwa kolaborasi guru mempunyai dampak positif tidak hanya bagi guru, tetapi juga bagi siswa dan sekolah. Dari sisi guru, kolaborasi berperan dalam meningkatkan kompetensi berupa pengetahuan, ketrampilan dan pengalaman guru. Selanjutnya kompetensi guru akan berperan dalam menunjang kinerja guru yang pada akhirnya akan meningkatkan prestasi siswa.
\end{abstract}

Kata Kunci : Kompetensi, Kolaborasi, Tinjauan Teoritis

\section{LATAR BELAKANG}

Kualitas sumber daya manusia dapat ditingkatkan salah satunya melalui pendidikan, baik formal maupun informal. Untuk itu, sekolah memegang peran penting dalam peningkatan tersebut. Keberhasilan pendidikan tidak bisa lepas dari peran guru dalam mendidik siswa. Sebagai konsekuensinya, guru harus senantiasa meningkatkan kompetensinya. Kompetensi tersebut merupakan kombinasi antara pengetahuan, ketrampilan, nilai-nilai moral dan kepercayaan guru (Pantic dan Wubbels, 2010). Peningkatan kompetensi seperti pengetahuan dan ketrampilan akan meningkatkan praktik mengajar guru (Selvi, 2010) sehingga mampu memfasilitasi kebutuhan siswa.

Peningkatan kompetensi bisa dilakukan guru melalui proses pembelajaran. Proses pembelajaran tersebut perlu dilakukan secara dinamis dan berkelanjutan di sepanjang karir guru dan tertanam dalam berbagai jenis konteks dan kegiatan misalnya di dalam ruang kelas, kursus, lokakarya pengembangan profesional maupun kolaborasi dengan rekan kerja (Pedder dan Opfer, 2014). 
Kolaborasi merupakan suatu tindakan kooperatif anggota sekolah untuk mencapai tujuan yang terkait dengan pekerjaan (Kelchtermans, 2006). Kualitas dan kuantitas kolaborasi merupakan salah satu elemen kunci dalam membuat profesi guru menjadi kuat, dimana profesionalisme yang kuat akan menentukan sistem pendidikan berkinerja tinggi (Hargreaves, 2019).

Kolaborasi yang dilakukan berpotensi sebagai akar rumput pendorong utama perubahan pendidikan (Barfield, 2016). Kegiatan kolegialitas merupakan aspek kunci pengembangan profesional guru dan sebagai sarana untuk meningkatkan pengetahuan (Shah, 2012), karena ketika kolaborasi efektif terjadi, pengetahuan dan pengalaman guru dibagikan dan pengajaran ditingkatkan. Pengalaman yang diperoleh dari kegiatan kolaborasi akan mengubah pengetahuan, sikap dan kepercayaan guru dan menghasilkan peningkatan instruksi dalam mengajar secara permanen maupun substansial (Samaranayake et al., 2018). Selain itu kolaborasi yang dilakukan secara profesional mampu membangun pengalaman, pedagogi dan pengetahuan konten (Goddard et al., 2007). Lebih jauh lagi, Glazier et al., 2016, setuju dengan kesimpulan National Commission on Teaching \& America's Future bahwa kolaborasi adalah kunci untuk karir guru yang bermanfaat dalam mengajak dan mempertahankan profesionalisme guru, berdampak pada pengajaran yang lebih baik dan pembelajaran siswa yang lebih dalam. Untuk itu sudah waktunya bagi para guru untuk memanfaatkan kekuatan kolaborasi di semua level dan profesi dalam rangka menuju kesuksesan abad 21.

Kerjasama dan kebersamaan dalam kolaborasi guru merupakan faktor penentu tidak hanya pengembangan profesional guru tetapi juga pengembangan sekolah (Kelchtermans, 2006). Peneltianpenelitian yang membahas mengenai kolaborasi guru lebih banyak dilakukan pada negara-negara maju dan lebih banyak mengaitkan dengan prestasi siswa, sedang keterkaitannya dengan kompetensi guru masih terbatas. Di sisi lain penelitian terkait kolaborasi guru dengan kompetensi pada negara berkembang khususnya Indonesia masih terbatas. Mengingat hal tersebut dan dampak positif kolaborasi terhadap guru, maka telaah ini perlu dilakukan untuk mengkaji bagaimana kolaborasi guru yang efektif dilakukan agar kualitas guru meningkat dari sudut pandang kompetensinya.

\section{TINJAUAN PUSTAKA}

Kompetensi guru dapat dikonsepkan sebagai kerangka kerja yang menggambarkan kualitas spesifik guru yang dibutuhkan untuk memenuhi tuntutan profesi yang tinggi (Fauth et al., 2019). Stoof, et al., 2002 mendefinisikan kompetensi sebagai seperangkat karakteristik individu yang terintegrasi, meliputi pengetahuan, ketrampilan dan sikap yang diperlukan untuk mencapai keefektifan kinerja dalam berbagai konteks pengajaran. Sedang Pantic dan Wubbels (2010) menjelaskan komponen dari kompetensi meliputi kombinasi pengetahuan, ketrampilan, nilai-nilai moral dan kepercayaan.

Kompetensi guru berfungsi sebagai pendorong utama untuk meningkatkan kualitas pengajaran dan hasil siswa (Kleickmann et al., 2013) sehingga bisa artikan bahwa kualitas pengajaran yang tinggi membutuhkan tingkat pengetahuan dan ketrampilan yang kuat (Blomeke et al., 2020). Kompetensi guru misalnya pengetahuan konten pedagogi, self-efficacy dan antusiasme mengajar mampu meningkatkan kualitas mengajar yang pada gilirannya akan meningkatkan hasil siswa (Fauth et al., 2019; Kaiser \& Konig, 2019).

Kolaborasi merupakan interaksi bersama dalam kelompok pada semua kegiatan yang diperlukan untuk melakukan tugas bersama (Vangrieken et al., 2015). Di pandang dari sudut lingkungan pendidikan, kolaborasi mengandung pengertian suatu tindakan kooperatif anggota sekolah untuk tujuan yang terkait dengan pekerjaan (Kelchtermans, 2006). Tindakan tersebut bisa berupa berbagi nilai melalui pembelajaran guru sehingga mampu mempengaruhi praktik mengajar dan prestasi siswa (Shakenova, 2017). Kolaborasi merupakan sarana bagi guru untuk saling mengingatkan tentang peran mereka, meningkatkan bahan ajar, praktik mengajar dan interaksi dengan siswa (Kafyulilo, 2013). Kegiatan kolaborasi dilakukan dengan melibatkan orang lain dalam menentukan tujuan bersama, berbagi tanggung jawab dan bekerja sama untuk mencapai lebih dari yang bisa dicapai secara mandiri (Barfield, 2016).

Manfaat utama dari kolaborasi guru yaitu meningkatkan kesempatan guru untuk tumbuh secara profesional melalui interaksi dengan orang lain (Pukkila et al., 2007), mampu meningkatkan 
pengetahuan dan ketrampilan guru (Egodawatte et al., 2011), sedang Johnson (2003) menjelaskan bahwa keuntungan yang dirasakan dengan adanya kolaborasi yaitu guru merasa mendapat dukungan moral dan kesempatan untuk belajar satu sama lain sehingga membantu guru merasa lebih baik tentang diri mereka sendiri dan tugas-tugasnya. Namun Johnson (2003) juga menegaskan ada kerugian dibalik kolaborasi seperti guru merasa beban kerja bertambah, guru kehilangan kemandirian dan otonomi, konflik antar pribadi serta terjadi kompetisi yang tidak sehat antar tim.

Lebih jauh lagi, kolaborasi guru tidak hanya bermanfaat bagi guru semata tetapi juga bermanfaat bagi siswa, sekolah, komunitas profesional seperti yang dikemukakan oleh Forte dan Flores (2014) yaitu :

1. Untuk guru, terjadi perubahan budaya profesional individualistis, kepuasan kerja dan motivasi.

2. Untuk siswa, terciptanya pengalaman baru, pengawasan pekerjaan siswa yang lebih baik, hasil siswa yang lebih baik.

3. Untuk sekolah, terjalin hubungan kerja dengan rekan kerja, reputasi/citra sekolah yang lebih baik, pengalaman pertukaran dengan sekolah lain dan kemitraan dengan entitas lokal.

4. Untuk masyarakat, berupa penyebaran informasi, hubungan yang lebih baik dengan komunitas. Vangrieken et al., (2015) juga sependapat bahwa kolaborasi guru bermanfaat bagi guru, siswa dan sekolah. Ditingkat guru manfaat kolaborasi guru misalnya terjadi kemajuan dalam kinerja, guru merasa kurang terisolasi, lebih termotivasi dan meningkatkan moral guru. Ditingkat siswa kolaborasi guru mampu menigkatkan kinerja siswa, sedang ditingkat sekolah terjadi perubahan budaya dan lebih inovatif.

Kafyulilo (2014) mengidentifikasi bentuk utama kolaborasi guru dalam rangka pengembangan profesional guru yaitu komunitas praktik, kelompok studi pelajaran, komunitas pembelajaran profesional dan desain tim guru. Kegiatan kolaborasi juga bisa berupa tatap muka, menggunakan mediasi digital maupun kombinasi keduanya, kegiatan yang dilakukan dalam sekolah atau institusi sama, lintas insitusi, lintas jaringan guru yang lebih luas baik ditingkat lokal, regional, nasional maupun internasional (Barfield, 2016). Lebih lanjut De Jong et al., (2019) mengkatagorikan jenis kolaborasi dari guru yang mandiri sampai guru lebih sering tergantung, yaitu :

1. Menceritakan atau memindai ide-ide dan sesekali terjadi pertukatan pengalaman di antara rekan kerja.

2. Bantuan dan timbal baliknya, merupakan interaksi guru dengan ketersediaan bantuan atau bantuan timbal balik.

3. Metode dan bahan berbagi, kolaborasi ini menyoroti berbagi materi dan metode berupa pemaparan materi dan metode yang berkaitan dengan kurikulum dan pengajaran sesama rekan kerja.

4. Kerja sama, interaksi guru dengan saling ketergantungan tingkat tinggi. Guru merasakan tanggung jawab bersama untuk tugas mengajar.

Keberlangsungan dan keberhasilan kolaborasi dipengaruhi banyak faktor. Faktor-faktor yang mempengaruhi kolaborasi guru menurut Silva dan Morgado (2005) yaitu :

1. Faktor pribadi dan profesional misalnya motivasi pribadi, keterbukaan terhadap pendapat yang berbeda, fleksibilitas, hubungan antara anggota tim, rasa tanggung jawab, kompetensi untuk berinovasi, rasa rendah hati, dan sukarela.

2. Suasana sosial dalam tim meliputi tujuan bersama, saling menghormati, kapasitas untuk mendengarkan saran dan pendapat orang lain, kualitas hubungan di antara anggota tim, kualitas proses komunikasi, kepercayaan pada satu sama lain, dan adanya kepemimpinan yang menjamin kohesi kelompok.

3. Faktor organisasi yang memfasilitasi kolaborasi guru yaitu jadwal guru, keberadaan sumber daya, definisi dan distribusi tugas, dukungan administrasi, dan keberadaan prosedur evaluasi. Sedang Shakenova (2017) menjelaskan, faktor-faktor yang mendorong kolaborasi guru yaitu : 
1. Kondisi struktural meliputi memiliki tujuan bersama, memiliki waktu formal dan informal untuk bertemu, kemampuan untuk berbagi dengan kolega yang memiliki lebih banyak pengalaman, kesempatan untuk saling mengamati, ruang fisik yang simpel serta tujuan bersama.

2. Dinamika interpersonal berupa dialog dan partisipasi aktif, kepercayaan, sikap positif terhadap pengajaran, memiliki kepercayaan dan pemahaman bersama, keterbukaan dan rasa hormat serta inisiatif guru.

Selain hal tersebut di atas, Vangrieken et al. (2015) menemukan bahwa faktor yang mendorong kolaborasi guru banyak ditemukan di tingkat proses kolaborasi misalnya mewujudkan interdependensi tugas, mengembangkan peran anggota secara jelas, dan fokus pada definisi kolaborasi. Diperlukan juga dukungan struktural untuk kolaborasi guru seperti menyediakan waktu dan intervensi tingkat kelompok. Namun juga ditemukan faktor yang menghambat kolaborasi misalnya aspek budaya dan elemen yang terkait dengan pola pikir guru misalnya budaya individualism, otonomi dan kemandirian yang kuat. Sementara itu, Shakenova (2017) menjelaskan faktor penghambat kolaborasi guru yaitu :

1. Waktu misalnya tidak cukup waktu untuk berbagi, kelebihan beban kerja, tidak cukup waktu untuk belajar, kurangnya waktu bersama dengan rekan kerja, dan kurangnya waktu untuk berbagi.

2. Mikropolitik, mengacu pada penggunaan kekuatan formal dan informal oleh individu dan kelompok untuk mencapai tujuan.

3. Budaya, berupa kolegialitas yang dibuat-buat, budaya kerjasama dalam waktu singkat tanpa nilai bersama.

Penelitian yang dilakukan oleh Shakenova (2017) menyimpulkan bahwa kolaborasi berpengaruh positif pada pembelajaran guru melalui berbagi pengalaman dan ide sehingga terjadi pengayaan pengetahuan mata pelajaran dan ketrampilan instruksional, yang pada gilirannya mempengaruhi kinerja siswa.

Voogt et al. (2016) melakukan penelitian terhadap 14 hasil penelitian mahasiswa tingkat doktoral terkait kolaborasi guru pada tim desain kurikulum. Penelitian yang dilakukan untuk melihat dampak kolaborasi terhadap pembelajaran guru dan perubahan kurikulum. Hasil menunjukkan bahwa kolaborasi tim desain kurikulum mempengaruhi pengetahuan guru misalnya konten pedagogis, pengetahuan desain serta mempengaruhi ketrampilan.

Penelitian terkait kegiatan kolaborasi guru terhadap 82 hasil penelitian sebelumnya dilakukan oleh Vangrieken et al (2015). Penelitian ini bertujuan antara lain untuk mengetahui manfaat kolaborasi guru, faktor pendorong dan penghambat budaya kolaborasi. Hasil penelitian menunjukkan bahwa kolaborasi guru bermanfaat ditingkat guru, siswa dan sekolah.

Neuberger (2012) melakukan penelitian untuk mengetahui manfaat kolaborasi antara guru dengan guru pembina tentang pendidikan matematika. Hasil penelitian menunjukkan bahwa kolaborasi meningkatkan keyakinan guru terkait pendidikan matematika yang pada akhirnya mempengaruhi guru dalam mengajar.

Shah (2012) melalukan penelitian tentang manfaat dan peran kolegialitas guru di sekolah. Menurut Kelchtermans (2006) istilah koligialitas dan kolaborasi sering digunakan secara bergantian. Hal ini mengindikasikan antara kolegialitas dengan kolaborasi mempunyai pengertian yang sama. Hasil penelitian menujukkan bahwa kolgialitas guru berperan penting dalam meningkatkan pengembangan profesional guru, kualitas sekolah dan kinerja siswa.

\section{METODE PENELITIAN}

Metode analisis penelitian ini adalah tinjauan literatur. Pengumpulan data melalui teknik kepustakaan berupa buku dan publikasi hasil penelitian berbentuk jurnal atau bentuk publikasi lainnya. Definisi kompentensi guru mengacu pada pendapat Stoof, Martens, Merriënboer, \& Bastiaens (2002) yaitu kompetensi merupakan seperangkat karakteristik individu yang terintegrasi yang meliputi pengetahuan, ketrampilan dan sikap yang diperlukan untuk mencapai keefektifan kinerja dalam 
berbagai konteks pengajaran. Pengertian kolaborasi mengacu pada pendapat Kelchtermans (2006) yaitu kolaborasi merupakan suatu tindakan kooperatif anggota sekolah untuk tujuan yang terkait dengan pekerjaan (Kelchtermans, 2006).

\section{HASIL DAN PEMBAHASAN}

Penelitian-penelitian yang dilakukan sebelumnya menyimpulkan bahwa kolaborasi guru mempunyai dampak positif bagi guru misalnya pengetahuan, ketrampilan, keyakinan guru, pengembangan profesional, kinerja guru (Shakenova, 2017; Voogt et al., 2016; Vangrieken et al., 2015; Neuberger, 2012; Shah, 2012), bagi siswa (Vangrieken et al., 2015; Shakenova, 2017; Shah, 2012) dan bagi sekolah (Vangrieken et al., 2015; Shah, 2012)

Mengingat manfaat kolaborasi tidak hanya bagi guru, tetapi juga bagi siswa dan sekolah, Hargreaves (2019) mengusulkan desain spesifik dalam meningkatkan aktivitas kolaborasi di sekolah yaitu melalui komunitas pembelajaran profesional, perencanaan kolaboratif, putaran pembelajaran, penyelidikan kolaboratif, studi pelajaran, jaringan sekolah, proses evaluasi diri, dan peer review. Aktivitas kolaborasi seperti perencanaan kolaborasi dalam tim perlu mendapat dukungan organisasi, dukungan proses dan dukungan ahli agar memcapai hasil yang berkualitas (Voogt et al., 2016).

Kolabroasi tidak hanya ditingkatkan tetapi juga perlu dipromosikan melalui beberapa strategi. Strategi tersebut dilakukan baik ditingkat organisasi maupun struktural misalnya penciptaan ruang, kondisi dan waktu untuk berkolaborasi, mendorong guru untuk mengubah individualismenya, menjalin kemitraan, penyebaran informasi kegiatan kolaborasi, pelatihan kolaborasi, mendorong penciptaan motivasi, profesionalitas dan karekteristik guru seperti keterampilan komunikasi, keterampilan kepemimpinan dan keterampilan mengajar (Forte dan Flores, 2014).

Sementara itu, Gajda dan Koliba (2008) merekomendasikan langkah-langkah untuk meningkatkan kolaborasi guru agar efektif yaitu (1) meningkatkan literasi kolaborasi, (2) mengidentifikasi dan menginventarisasi kegiatan, (3) mengkonfigurasi ulang tim guru, (4) menilai kualitas kolaborasi, (5) melakukan koreksi dan (6) menghargai prestasi. Namun langkah-langkah tersebut bukan merupakan garis lurus tetapi tergantung pada faktor lingkungan, budaya, kapasitas teknologi dan kepala sekolah.

Selain itu, cara yang ditempuh untuk menciptakan kolaborasi efektif yaitu melalui dukungan dari pimpinan dan melibatkan guru dalam pencarian kegiatan kolaboratif, oleh karena itu pembuat kebijakan perlu terlibat dalam membangun kolaborasi dalam jangka panjang sebagai konteks untuk menerapkan kebijakan (Hargreaves, 2019). Dari sisi guru, agar proses kolaboratif berjalan efektif, maka diharapkan guru memiliki pegetahuan dan ketrampilan yang tepat serta guru mempunyai peran yag jelas misalnya keadilan dalam distribusi tanggung jawab, inovasi dan komunikasi tim (Vangrieken et al., 2015). Dari sisi pimpinan, dukungan pimpinan seperti dukungan terhadap proses dan desain berpengaruh terhadap keberhasilan dan keberlanjutan kolaborasi misalnya kolaborasi desain kurikulum (Voogt et al., 2016). Dikuatkan oleh Goddard et al. (2010) bahwa kepemimpinan yang baik dalam mendukung kolaborasi efektif untuk peningkatan sekolah yaitu pemimpin yang berada di dalam dan di luar lingkup sekolah dimana pemimpin sekolah harus melibatkan guru dalam berkolaborasi. Selanjutnya dijelaskan bahwa kolaborasi tersebut akan lebih produktif jika kepala sekolah terlibat dalam pemantauan kelas dan berbagi kepemimpinan dengan guru.

Selain mengusahakan agar kolaborasi guru efektif, pembinaan kolaborasi perlu dilakukan untuk memberi manfaat dalam jangka panjang. Pendekatan spesifik untuk membina kolaborasi dilakukan melalui pendampingan guru, komunitas personal atau komunitas pembelajaran profesional, menciptakan kepemimpinan bersama diantara kepala sekolah dan guru (Schleifer, Rinehart, \& Yanisch, 2017) , selanjutnya di masa depan, bentuk kolaborasi guru harus berkonsentrasi pada kerjasama guru dan rasa tanggung jawab bersama untuk meningkatkan praktik pengajaran (De Jong et al., 2019). Sedang Mccarthy, Brennan, \& Vecchiarello (2011) menyarankan langkah-langkah untuk membina hubungan kolaboratif yaitu (1) mendefinisikan peran dan tanggung jawab (2) membangun visi bersama, (3) menetapkan rencana strategis kolaboratif dan (4) menilai dan menyesuaikan rencana. 


\section{KESIMPULAN}

Kolaborasi guru diperlukan di era globalisasi yang menuntut perubahan dan peningkatan berkelanjutan. Kolaborasi guru memberi kesempatan untuk melibatkan banyak guru dalam menyelesaikan masalah kependidikan yang semakin komplek. Interaksi yang terjadi saat kolaborasi memberi kesempatan guru tumbuh secara profesional (Pukkila et al., 2007). Artinya kolaborasi merupakan aspek kunci pengembangan profsional guru dan sebagai sarana untuk meningkatkan pengetahuan guru (Shah, 2012). Karena kolaborasi yang efektif dapat menciptakan terjadinya aktivitas berbagi pengetahuan dan pengalaman (samaranayake et al. 2018). Pengetahuan dan pengalaman guru merupakan kompetensi yang dimiliki guru untuk mencapai keefektifan kinerja (Stoof et al., 2002). Selanjutnya kompetensi akan mendorong peningkatan kualitas pengajaran dan kinerja siswa (Kleickmann et al., 2013). Pada akhirnya kolaborasi guru merupakan pendorong utama perubahan pendidikan (Barfield, 2016) melalui kompetensi guru.

Hal tersebut menunjukkan bahwa meletakkan dasar kolaborasi guru sangat penting bagi sekolah. Peranan pimpinan dalam mendukung kolaborasi guru akan menciptakan kolaborasi yang efektif. Untuk mendapatkan manfaat dalam jangka panjang, kolaborasi guru perlu dipromosikan, ditingkatkan dan dibina.

\section{DAFTAR PUSTAKA}

Barfield, A. (2016). Collaboration. ELT Journal, 70(2), 222-224. https://doi.org/10.1093/elt/ccv074 de Jong, L., Meirink, J., \& Admiraal, W. (2019). School-Based Teacher Collaboration: Different Learning Opportunities Across Various Contexts. Teaching and Teacher Education, 86, 1-12. https://doi.org/10.1016/j.tate.2019.102925

Egodawatte, G., McDougall, D., \& Stoilescu, D. (2011). The Effects of Teacher Collaboration in Grade 9 Applied Mathematics. Educational Research for Policy and Practice, 10, 189-209. https://doi.org/10.1007/s10671-011-9104-y

Fauth, B., Decristan, J., Decker, A. T., Büttner, G., Hardy, I., Klieme, E., \& Kunter, M. (2019). The Effects of Teacher Competence on Student Outcomes in Elementary Science Education: The Mediating Role of Teaching Quality. Teaching and Teacher Education, 86, 102882. https://doi.org/10.1016/j.tate.2019.102882

Forte, A. M., \& Flores, M. A. (2014). Teacher Collaboration and Professional Development in the Workplace: A Study of Portuguese Teachers. European Journal of Teacher Education, 37(1), 91105. https://doi.org/10.1080/02619768.2013.763791

Gajda, R., \& Koliba, C. J. (2008). Evaluating and Improving the Quality of Teacher Collaboration: A Field-Tested Framework for Secondary School Leaders. NASSP Bulletin, 92(2), 133-153. https://doi.org/10.1177/0192636508320990

Glazier, J. A., Boyd, A., Bell Hughes, K., Able, H., \& Mallous, R. (2016). The Elusive Search for Teacher Collaboration. New Educator, 13(1), 3-21. https://doi.org/10.1080/1547688X.2016.1144841

Goddard, Y. L., Goddard, R. D., \& Tschannen-Moran, M. (2007). A Theoretical and Empirical Investigation of Teacher Collaboration for School Improvement and Student Achievement in Public elementary schools. Teachers College Record, 109(4), 877-896.

Goddard, Y. L., Madsen, J., Larson, R., \& Goddard, R. (2010). Connecting Principal Leadership, Teacher Collaboration, and Student Achievement. Paper was presented at the Annual Meeting of the American Educational Research Association,

Hargreaves, A. (2019). Teacher Collaboration: 30 Years of Research on its Nature, Forms, Limitations and Effects. Teachers and Teaching, 25(5), 1-19.

https://doi.org/10.1080/13540602.2019.1639499

Johnson, B. (2003). Teacher Collaboration: Good for Some, Not So Good for Others. Educational 
Studies, 29(4), 337-350. https://doi.org/10.1080/0305569032000159651

Kafyulilo, A. C. (2013). Professional Development Through Teacher Collaboration : An Approach to Enhance Teaching and Learning in Science and Mathematics in Tanzania. Africa Education Review, 10(4), 671-688. https://doi.org/10.1080/18146627.2013.853560

Kaiser, G., \& Konig, J. (2019). Competence Measurement in (Mathematics) Teacher Education and Beyond: Implications for Policy. Higher Education Policy, 32(4), 597-615. https://doi.org/10.1057/s41307-019-00139-z

Kelchtermans, G. (2006). Teacher Collaboration and Collegiality as Workplace Conditions. A Review. Zeitschrift Fur Padagogik, 52(2), 220-237.

Kleickmann, T., Richter, D., Kunter, M., Elsner, J., Besser, M., Krauss, S., \& Baumert, J. (2013). Teachers' Content Knowledge and Pedagogical Content Knowledge: The Role of Structural Differences in Teacher Education. Journal of Teacher Education, 64(1), 90-106. https://doi.org/10.1177/0022487112460398

Mccarthy, P. J., Brennan, L., \& Vecchiarello, K. (2011). Parent - School Communication in the Inclusive Classroom : A Comprehensive Model of Collaboration in Education. International Journal of Humanities and Social Science, 1(15), 55-60.

Neuberger, J. (2012). Benefits of a Teacher and Coach Collaboration: A Case Study. Journal of Mathematical Behavior, 31(2), 290-311. https://doi.org/10.1016/j.jmathb.2011.12.004

Pantic, N., \& Wubbels, T. (2010). Teacher Competencies as a Basis for Teacher Education - Views of Serbian Teachers and Teacher Educators. Teaching and Teacher Education, 26(3), 694-703. https://doi.org/10.1016/j.tate.2009.10.005

Pedder, D., \& Opfer, V. D. (2014). Professional Learning Orientations: Patterns of Dissonance and Alignment between Teachers' Values and Practices. Research Papers in Education, 28(5), 539570. https://doi.org/10.1080/02671522.2012.706632

Pukkila, P., DeCosmo, J., Swick, D. C., \& Arnold, M. S. (2007). How to Engage in Collaborative Curriculum Design to Foster Undergraduate Inquiry and Research in All Disciplines. In Developing and Sustaining a Research-Supportive Curriculum: A Compendium of Successful Practices (pp. 341-357).

Samaranayake, G., Premadasa, K., Amarasinghe, R., \& Paneru, K. (2018). Teacher Change Through Lesson Study Collaboration. International Journal for Lesson and Learning Studies, 7(4), 263276.

Schleifer, D., Rinehart, C., \& Yanisch, T. (2017). Teacher Collaboration in Perspective : A guide to Research. Retrieved from http://www.in-perspective.org/pages/ teacher-collaboration

Selvi, K. (2010). Teachers' Competencies. International Journal of Philosophy of Culture and Axiology, VIII (1), 167-176.

Shah, M. (2012). The Importance and Benefits of Teacher Collegiality in Schools - A Literature Review. Procedia - Social and Behavioral Sciences, 46, 1242-1246. https://doi.org/10.1016/j.sbspro.2012.05.282

Shakenova, L. (2017). The Theoretical Framework of Teacher Collaboration. Khazar Journal of Humanities and Social Sciences, 20(2), 34-48. https://doi.org/10.5782/2223-2621.2017.20.2.34

Silva, J. C., \& Morgado, J. (2005). Facilitators To Collaboration Between Teachers: Effects of Gender, Teaching Experience and Subject Area. In Inclusive and Supportive Education Congress International Special Education Conference Inclusion: Celebrating Diversity? (pp. 1-17).

Stoof, A., Martens, R. L., Merriënboer, J. J. G. Van, \& Bastiaens, T. J. (2002). The Boundary Approach of Competence: A Constructivist Aid for Undertanding and Using the Concept of Competence. Human Resource Development Review, 1(3), 345-365.

Vangrieken, K., Dochy, F., Raes, E., \& Kyndt, E. (2015). Teacher Collaboration: A Systematic Review. Educational Research Review, 15, 17-40. https://doi.org/10.1016/j.edurev.2015.04.002

Voogt, J. M., Pieters, J. M., \& Handelzalts, A. (2016). Teacher Collaboration in Curriculum Design Teams : Effects , Mechanisms , and Conditions. Educational Research and Evaluation, 22(3-4), 121-140. https://doi.org/10.1080/13803611.2016.1247725 